\title{
REPRESENTAÇÃO SUBSTANTIVA DE GÊNERO E RAÇA NO BRASIL: ANÁLISE DE CASOS
}

\author{
Substantive representation of gender and race in Brazil: Case Study
}

\author{
Orlando Lyra de Carvalho Júnior ${ }^{1}$ \\ Pamela Dias Villela Alves ${ }^{2}$
}

\section{Resumo}

As dinâmicas da representação parlamentar no Brasil suscitam uma questão central: em que medida quem ocupa os cargos afeta os tipos de políticas aprovadas? Dado que as evidências empíricas não são conclusivas sobre tal questão, este artigo propôs-se analisar a efetividade da representação descritiva de gênero e de "raça" na Câmara dos Deputados e em Assembleias Legislativas de sete estados (legislatura 2015-2019), utilizando para isso um questionário de 65 itens que foi aplicado a uma amostra aleatória de 300 Membros do Parlamento. Um "índice de produção legislativa específica", baseado na taxa de sucesso das proposições transformadas em leis, foi criado como proxy de representação substantiva. Índices significativamente maiores de produção legislativa específica foram encontrados entre as/os representantes descritiva/os $(M=1.95 / 0.27)$, o que sugere uma forte correlação entre as duas formas de representação. As variáveis "gênero" $(\operatorname{Exp}(B)=5,497)$ e "ideologia" $(\operatorname{Exp}(B)=14,149)$ mostraram-se especialmente robustas como preditoras de representação substantiva. Palavras-Chave: Representação descritiva e substantiva, Gênero, "Raça".

\begin{abstract}
The dynamics of parliamentary representation in Brazil raises a central question: to what extent who occupies seats in Parliament affects legislation approval? Given that empirical evidence has not been conclusive on this issue, the article proposes to analyze the effectiveness of the descriptive representation of women and non-white in the Chamber of Deputies and State Assemblies of seven states (legislature 2015-2019). An elite survey of 65 items was applied to a randomized sample of 300 MPs. A "specific legislative production index" was created based on the success rate of propositions transformed into laws. Significantly higher rates of specific legislative output were found among descriptive MPs ( $M=1.95 / 0.27)$, suggesting a strong connection between the two forms of representation. The variables "gender" $(\operatorname{Exp}(B)=5.497)$ and "ideology" $(\operatorname{Exp}(B)=14,149)$ were especially robust as predictors of substantive representation.
\end{abstract}

Keywords: Descriptive and substantive representation, Gender, "Race".

\footnotetext{
1 Doutor em Ciência Politica (Uni-Bamberg, Alemanha) e Pós-doutorado em Sociologia Política (UVV). https://orcid.org/0000-0002-0281-9832. E-mail: orlandolyra@gmail.com. Universidade Vila Velha. Av. Comissário José Dantas de Melo, 21, 29102-920, Vila Velha, ES, Brasil.

2 Especialista em Gestão de Políticas Públicas em Gênero e Raça (UFMG). https:orcid.org/0000-00022448-8114. E-mail: pamvillela@gmail.com. Universidade Federal de Juiz de Fora, Rua José Lourenço Kelmer, s/n - São Pedro, Juiz de Fora - MG, 36036-900.
} 


\section{Introdução ${ }^{3}$}

Campo historicamente dominado por homens brancos, a politica está estruturada de forma a possibilitar a reprodução e a institucionalização das hierarquias de gênero e "raça". O próprio ethos politico privilegia valores e crenças associados à masculinidade e à brancura da pele, prejudicando consideravelmente a aspiração política de mulheres e não-brancos, ainda nas etapas iniciais do processo eleitoral. A dupla, tripla e até quíntupla jornada de trabalho e as dificuldades de conciliar a vida privada com as exigências da competição política -- que em geral demandam longas e imprevisiveis horas de trabalho -- fazem com que o ingresso na carreira politica seja um privilégio para algumas poucas mulheres. Isso é agravado pelo fato de que o sistema eleitoral brasileiro, baseado em listas abertas, torna as campanhas mais caras e, portanto, inacessiveis para a maioria das mulheres e negros, os quais, em geral, são preteridos, discriminados ou utilizados como "laranjas" para financiar as campanhas milionárias de homens brancos. Não espanta que movimentos feministas e negros de há muito lutem por modificações no sistema eleitoral que favoreçam candidaturas femininas e de não-brancos, como, por exemplo, a instituição da lista fechada com alternância de sexo e cor da pele.

A escolha da representação parlamentar de mulheres e não-brancos como tema deste estudo se deve ao fato de que, do ponto de vista histórico, mecanismos semelhantes de discriminação incidem sobre o gênero e a "raça" de candidatos e candidatas, embora com dinamismos e intensidades diferentes. Por um lado, as relações de gênero perpassam todas as relações sociais, o que significa dizer que os seus efeitos se verificam não apenas entre as mulheres, mas em toda ordem social e politica. Por outro, a estratificação social baseada na cor da pele cria situações objetivas de desqualificação e sofrimento existencial para as pessoas não-brancas, situações essas que abrem as portas para práticas preconceituosas e discriminatórias. Muitas vezes insidiosas e sub-reptícias, tais práticas

\footnotetext{
${ }^{3}$ Agências de Fomento: Fundação de Inovação e Amparo à Pesquisa do Espírito Santo (FAPES) e Coordenação de Aperfeiçoamento de Pessoal de Nivel Superior (CAPES). Processo: $n^{\circ}$ $688855583 / 2014$.
} 
causam a inefetividade do sistema jurídico-legal, dado que mecanismos discriminatórios latentes continuam a reproduzir a estratificação social de gênero e "raça" a despeito do elenco de medidas protetivas e punitivas existentes no país. ${ }^{4}$

Portanto, a análise dos mecanismos de reprodução das desigualdades de gênero e "raça" no âmbito da representação parlamentar apresenta o claro desafio de se investigar as condições reais de êxito eleitoral de candidaturas de mulheres e pessoas negras em geral, em contextos políticopartidários nos quais prevalecem direitos formalmente iguais. Foi a partir das contribuições de pesquisadoras inglesas, norte-americanas, canadenses e alemãs, notadamente aquelas alinhadas com o "feminismo negro", que se passou a analisar os mecanismos responsáveis pela "dupla discriminação" de gênero e "raça" operantes no interior dos sistemas legais norte-americano e europeu, em consequência dos quais mulheres negras experimentavam um tipo de alijamento socioeconômico similar ao experimentado por mulheres brancas, as quais, por sua vez, compartilhavam experiências semelhantes àquelas de homens negros. Descobriu-se que a violência e as múltiplas discriminações experimentadas por mulheres em todo mundo eram, muitas vezes, moldadas por outras dimensões de suas identidades, como raça e classe ${ }^{5}$ (CRENSHAW, 1989, 1994, 2002 e 2010; HOOKS, 1999; HUTCHINSON, 1999; BILGE, 2010; MOREIRA, 2017).

A característica central dos mecanismos sociais geradores da "dupla discriminação" (CRENSHAW, 1989) é que os sistemas de dominação não operam de forma isolada: diferentes fatores de exclusão atuam simultaneamente sobre as pessoas, dependendo das relações assimétricas de poder nas quais as diversas identidades individuais se encontram. Tal

\footnotetext{
4 Por exemplo: Lei $\mathrm{n}^{\circ} 7.716$, de 5 de janeiro de 1989, que regula os crimes de racismo; Estatuto da Igualdade Racial, lei $\mathrm{n}^{\circ}$ 12.228, de 20 de julho de 2010; Lei $\mathrm{n}^{\circ}$ 13.104, de 9 de março de 2015, que altera o art. 121 do Decreto-Lei no 2.848, de 7 de dezembro de 1940 (Código Penal), para prever o feminicídio como circunstância qualificadora do crime de homicídio, e o art. 1o da Lei no 8.072, de 25 de julho de 1990, para incluir o feminicídio no rol dos crimes hediondos.

5 É preciso notar, entretanto, que Crenshaw (1994/1989) focaliza sobretudo as intersecções de raça e gênero, abordando parcial ou perifericamente classe ou sexualidade, razão pela qual a categoria "classe" não foi objeto de análise teórica mais aprofundada neste artigo, embora apareça nas questões do survey utilizado na pesquisa.
} 
fato põe em xeque a ficção liberal de que os indivíduos gozam de direitos iguais a partir de experiências sociais semelhantes. O que a realidade mostra é que as pessoas estão sujeitas a múltiplas determinações em sua experiência social em função das diferentes posições dentro das estruturas de poder que ocupam.

Observa-se, por exemplo, que homens negros sofrem exclusão social em consequência da discriminação racial. Entretanto, esses mesmos indivíduos podem se beneficiar do sistema patriarcal e da cultura machista predominante, fato que diferencia suas experiências daquelas vivenciadas por mulheres negras. Por sua vez, as estatísticas mostram que mulheres brancas e negras sofrem das consequências da cultura sexista, e que a violência doméstica não atinge exclusivamente mulheres negras. Porém, as mesmas estatísticas mostram que as mulheres brancas têm mais chances e oportunidades na vida e são menos discriminadas do que as negras (IBGE, 2014; IPEA, 2017 e CATHO, 2017).

Partindo de tais pressupostos, teóricos do feminismo negro formularam uma teoria de discriminação que aborda a convergência do racismo e do sexismo como variáveis de exclusão social. A teoria da "discriminação interseccional" analisa as correlações empíricas e teóricas entre gênero e raça em diferentes contextos políticos e culturais. Segundo Sirma Bilge (2010), a interseccionalidade é um conceito transdisciplinar que visa estudar a complexidade das identidades e desigualdades sociais através de um enfoque integrado que rejeita o enclausuramento dos eixos de diferenciação social representados pelas categorias de gênero e raça. A abordagem interseccional procura, assim, ultrapassar a mera constatação dos mecanismos de opressão que operam a partir dessas categorias ao postular sua interação na produção e reprodução das discriminações e das desigualdades sociais e políticas.

A abordagem interseccional tem consequências teóricas e práticas importantes. Em primeiro lugar, ela sugere que os esforços feministas para dar uma dimensão pública às experiências de mulheres e os esforços antirracistas para politizar as experiências de negros perdem consideravelmente em poder explanatório e eficácia política se tais 
experiências forem consideradas como mutuamente exclusivas. Isso porque o racismo e o sexismo se cruzam no cotidiano e na vida de pessoas, embora nem sempre façam parte das práticas feministas e antirracistas. Por isso, a extensão da vulnerabilidade interseccional de gênero e raça, bem estudada na esfera privada da estrutura social, especialmente no mercado de trabalho, permanece pouco conhecida no contexto parlamentar brasileiro, o que pede um maior aprofundamento teórico e empírico da questão.

Em segundo lugar, a incorporação das variáveis gênero e raça nesta pesquisa procura realçar as formas pelas quais candidatos e candidatas a cargos eletivos proporcionais são afetados pela "dupla discriminação" (CRENSHAW, 1989) e por estigmas e estereótipos correlatos. Portanto, a inclusão de tais categorias no contexto da representação parlamentar tem o potencial de trazer à tona as inúmeras formas de discriminação e preconceito sofridos por homens e mulheres, no periodo pré-eleitoral e póseleitoral, em consequência do gênero e da cor da pele.

\section{Conceitos}

Os termos "gênero" e "raça" são aqui empregados como categorias de análise política. Em sentido amplo, gênero é uma categoria de análise histórica que estrutura a percepção e a organização concreta e simbólica da vida social. Mais especificamente, entendemos gênero não só como elemento constitutivo das relações sociais baseadas nas diferenças percebidas entre os sexos, mas também como forma primária de dar significado às relações de poder. Isso significa dizer que as distinções biológicas entre as pessoas adquirem maior ou menor relevância sócio-política em função da capacidade que um determinado grupo social tem de universalizar sentidos culturais através de processos de significação social. Em tal perspectiva, "gênero" se refere às significações culturais atribuídas a certos traços físicos, as quais, por sua vez, indicam diferentes formas de pertencimento e status sóciopolítico. Tal conceito possibilita visibilizar o gênero e a raça enquanto elementos discursivos das práticas que homens e mulheres vivenciam na construção das instituições politicas (SCOTT, 1995). 
Por "democracia de gênero" nos referimos a um conjunto de ideias gestadas, na década de 1990, em países Europeus, como a Alemanha (Geschlechterdemokratie), nos Estados Unidos (engendered Society) e no mundo de fala hispânica (el nuevo pacto entre los géneros), que propõe uma mudança no contrato social entre os sexos. A democracia de gênero tem como objetivo criar condições para o progresso em direção à igualdade de gênero através da responsabilidade compartilhada entre homens e mulheres em espaços públicos e privados. Igualdade ou equidade de gênero, por sua vez, se refere à distribuição justa dos direitos, oportunidades, recursos, responsabilidades e tarefas entre os gêneros, respeitando as diferenças entre mulheres e homens. Em termos de conteúdo e objetivos, "democracia de gênero" é sinônimo de "igualdade de gênero" (GOMÁRIZ e MEENTZEN, 2003).

Democracia de gênero, portanto, envolve a democratização das relações interpessoais sem a qual é impossivvel aprofundar a democratização das sociedades no âmbito público e privado, bem como nos processos de institucionalização democrática. A vantagem semântica da utilização do termo "democracia de gênero" é a legitimidade quase universal que a expressão "democracia" adquiriu após sucessivas “ondas” de democratização global, muito embora as múltiplas fontes nas quais a democracia moderna se fundamenta gere hermenêuticas conflitantes derivadas da polissemia da expressão.

A “democracia” a qual nos referimos não pode ser limitada ou definida apenas por seus procedimentos. A democracia comporta um conjunto de instituições, valores e princípios através dos quais atores sociais de diferentes grupos e culturas se fazem presentes no mundo político. Enquanto horizonte de valores, ela comporta principios éticos que empoderam os "sem poder" frente às desigualdades econômicas e sociais geradas pelo caráter assimétrico do poder político (TOURAINE, 2007; DAHL, 2012).

O termo "raça", por sua vez, deve ser entendido no contexto da "politica de identidade" (PLUTZER e ZIPP, 1996), o qual se refere às alianças politicas formadas com base em alguma semelhança demográfica. Aplicada 
à demografia racial, a política de identidade utiliza a noção de uma origem racial comum para alavancar políticas públicas, incluindo a eleição de candidatos com identificações raciais politizadas. Procura-se, assim, entender as relações entre a sub-representação não-branca e as variáveis contextuais como sexo, cor da pele, educação, classe social e ideologia sobre a estratificação racial. Entretanto, os significantes representados pela variável "não-brancos" não devem ser entendidos como categorias biológicas separadas de sua incorporação histórica, cultural e política. Pelo contrário, trata-se precisamente de analisá-los como são historicamente construídos através da política.

É nesse sentido que a "dupla discriminação" (CRENSHAW, 1989) é aqui entendida como todo tipo de tratamento, consciente ou inconsciente, intencional ou não, que coloca determinados grupos sociais (mulheres e não-brancos) em uma situação de desvantagem econômica, política e social. Portanto, o elemento central do conceito de "dupla discriminação" é a ideia de "desvantagem induzida", a qual pode ocorrer tanto no nivel microssocial, em consequência de comportamentos intencionais das pessoas, quanto no nível macrossocial, em virtude de arranjos institucionais, que operam independentemente da vontade dos indivíduos. Vale ainda salientar que, enquanto fenômenos sociais, o sexismo e o racismo operam como sistemas de dominação social que legitimam a subordinação de grupos marginalizados através da naturalização de hábitos discriminatórios, da formação de estereótipos e preconceitos e da criação de desigualdades de status econômico e cultural.

Dada a relevância teórica e prática dessa discussão, este artigo pretende investigar em que medida a representação de gênero e "raça" leva à defesa dos direitos e a promoção dos interesses de mulheres e pessoas negras, bem como avaliar o papel da ideologia autodeclarada dos representantes em tal relação. Mais especificamente, visa testar a efetividade da correlação entre aquilo que, segundo a tipologia de Hanna Pitkin (1966), se convencionou chamar de "representação descritiva" e o conteúdo do que é 
legislado (representação substantiva), na Câmara dos Deputados e em Assembleias Legislativas do país.

\section{Recorte teórico e hipótese}

Um dos principais problemas identificados na representação politica contemporânea diz respeito à sub-representação de determinados grupos sociais. No Brasil, nem mesmo a expansão da franquia eleitoral, com a incorporação de novos grupos -- como mulheres, trabalhadores e analfabetos -- à cidadania política, conseguiu modificar de maneira substantiva tal situação. Assim, não basta eliminar as barreiras à inclusão, como propõe o modelo liberal de democracia: é necessário incorporar ao corpo político, de modo efetivo, os grupos sociais historicamente marginalizados.

De fato, a afirmação da relevância política dos grupos sociais minoritários contradiz o dogma liberal do individualismo metodológico e abstrato, base do pensamento politico liberal. O rompimento com tal tradição politica foi teoricamente empreendido por muitos pensadores e pensadoras que passaram a avaliar o déficit de representatividade das instituições democráticas pelo gênero e etnia das/os representantes eleitas/os. Implícita em tais abordagens está a suposição de que instituições politicas com baixa representatividade de grupos historicamente desfavorecidos são injustas. E o debate normativo sobre a representação politica muitas vezes presume que uma representação substantiva adequada exigiria uma representação descritiva mais proporcional (PHILLIPS, 1995; YOUNG, 2000; KROOK e ZETTERBERG, 2014).

Hanna Pitkin (1967) assinala que a ideia de representação descritiva ${ }^{6}$ concebe o parlamento como uma espécie de "mapa", que representaria uma imagem perfeita da sociedade, embora em tamanho reduzido. Segundo a autora, tal representatividade "mimética" acabaria por promover a responsividade em detrimento da accountability, ${ }^{7}$ que seria substituída pela

\footnotetext{
6 Atualmente, "representação descritiva" se tornou sinônimo de "representação de grupo", "política de presença" ou ainda "auto representação", termos que aqui são usados indistintamente.

7 O conceito de accountability é sinônimo de responsabilidade objetiva, isto é, a obrigação de se responder a algo ou alguém. Implica, portanto, na responsabilização pessoal por atos praticados e a
} 
"similitude". Assim, as decisões politicas corresponderiam à vontade dos eleitores simplesmente porque seriam tomadas por pessoas similares a eles. Com isso, ainda segundo a autora, "o que" os representantes fazem perderia importância em relação a "quem" eles são. Nessa lógica, um critério valioso da representação politica, a prestação de contas dos representantes para com os seus representados, poderia vir a ser prejudicado em relação ao critério da similitude.

Já Anne Phillips (1995) prefere descrever a "política de presença" enquanto adoção de "quotas de representação" ou "presença física no Parlamento" para integrantes de determinados grupos sociais historicamente marginalizados da política, o que não excluiria a necessidade desses representantes descritivos passarem pelo crivo eleitoral e assim prestar contas aos seus eleitores. Portanto, a "similitude" seria um complemento à accountability, não a sua negação: os representantes descritivos continuariam dependentes do voto popular, mas os interesses de grupos marginalizados do ponto de vista representativo, mas majoritários, em termos demográficos, seriam levados em conta graças à sua presença nos espaços decisórios. Isso porque a sanção de que os eleitores dispõem o poder de retirar ou manter as/os representantes nos seus cargos a cada eleição - tem sido insuficiente para garantir a responsividade da representação parlamentar. De fato, a mera accountability vertical mostrouse incapaz de proteger os grupos marginalizados mesmo nas democracias ditas “avançadas”.

Iris Young (2000), por sua vez, observa que, quando a vida politica é pensada exclusivamente em termos de "promoção de interesses", fórmulas eleitorais que visam assegurar a presença de determinados grupos nas esferas de poder perdem força. A autora argumenta que, se, por um lado, cada um é o melhor juiz dos seus próprios interesses, então, os grupos hoje marginalizados não precisariam de nada para além da mera igualdade

exigência de prestação de contas. Na ciência política, accountability horizontal diz respeito ao controle que os poderes estabelecidos exercem uns sobre os outros. Accountability vertical se relaciona à necessidade que os representantes têm de prestar contas e submeter-se ao veredicto da população em eleições livres e periódicas. 
política formal para eleger os seus representantes, não existindo a necessidade de medidas especiais.

Para contornar o problema, Young (2000) propôs uma "perspectiva social" em vez de uma abordagem baseada apenas na promoção de interesses individuais ou coletivos: a representação política de grupos marginalizados é necessária não só porque os seus integrantes compartilham dos mesmos interesses, mas também porque compartilha de uma mesma "perspectiva social", ou seja, uma visão de mundo determinada por certos padrões socialmente estruturados de experiências de vida. A ideia de "perspectiva" permite captar a sensibilidade da experiência formada pela posição do grupo sem postular um conteúdo homogêneo.

A abordagem de Iris Marion Young (2000) sobre a representação descritiva é metodologicamente atraente por agregar um cluster de variáveis - interesses, opiniões e perspectivas sociais - que se aproxima da realidade empírica da representação política. Interesses, entendidos como meios necessários à consecução de fins individuais e coletivos; opiniões e valores, que fundamentam as decisões políticas; perspectivas e experiências sociais, que justificam a presença física de grupos minoritários no Parlamento. Desse modo, os diversos grupos sociais podem participar das esferas decisórias ao trazer para o debate politico interesses compartilhados, opiniões e experiências de vida que lhes são mais sensiveis (YOUNG, 2000, p. 134-136).

Do ponto de vista empírico, pesquisas realizadas em vários países europeus demonstram que a representação descritiva de mulheres e minorias étnicas contribui significativamente para o fortalecimento dos interesses desses grupos sociais (WÄNGNERRUND, 2009; CELIS e CHILDS, 2008). Em Portugal, por exemplo, depois da aprovação da Lei da Paridade em 2006, a representação feminina na Assembleia da República passou de $21,3 \%$ em 2005 para 33\% em 2015. Tal percentual se refletiu tanto na composição da atual Mesa Diretora do Parlamento (44\%) quanto na ocupação de altos postos em diferentes áreas governamentais $(30,5 \%)^{8}$. Entretanto, pesquisas revelam dinâmicas de mudanças e de continuidade

8 CIG, 2017. 
em consequência dessa representação mais equitativa: avanços na agenda política ao lado de uma persistente "genderização da organização política", que continua dominada pelo masculino (SANTOS e ESPÍRITO-SANTO, 2017).

Na Argentina, país pioneiro na legalização de mecanismo de cotas eleitorais para mulheres, ${ }^{9}$ pesquisadores também chegaram a resultados ambivalentes: a porcentagem de deputadas no Congresso unicameral chegou a 38.3\% em 2007 (LLANOS e SAMPLE, 2008, p. 14), gerando efeitos positivos para a representação substantiva dos interesses das mulheres. Mas essa mesma política de cotas também serviu para reforçar estereótipos negativos sobre a capacidade das mulheres de atuar no campo político, uma vez que, sem as cotas, provavelmente não teriam o mesmo desempenho nas urnas (FRANCESCHET e PISCOPO, 2008).

Já em outros países, a representação descritiva não se traduziu em incremento de representação substantiva, como é o caso dos Estados Unidos, onde variáveis concorrentes, como a filiação partidária e o status socioeconômico, continuam a ser decisivos para o sucesso eleitoral dos candidatos. Daí que o problema central da democracia representativa moderna é permitir a expressão de interesses, opiniões e perspectivas sociais hoje excluídas ou marginalizadas das esferas de poder (Swain, 1993).

Outro aspecto da representação de grupos é a natureza multifuncional de qualquer representação política nas sociedades modernas: o mandato concedido aos representantes, descritivos ou não, comporta um leque indeterminado de questões e problemas públicos, geralmente envolvendo questões técnicas de alta complexidade, que devem ser resolvidos. Isso implica na participação em centenas de processos deliberativos ao longo da legislatura. Do ponto de vista dos eleitores, os custos da informação são elevados, dado que apenas uma pequena parcela dos constituintes dedica tempo e atenção para acompanhar a agenda dos debates políticos.

Assim, a multifuncionalidade da representação significa múltiplas prestações de conta. O eleitor médio não é capaz de acompanhá-las e

\footnotetext{
${ }^{9}$ Ley de Cupo Feminino, n. 24.012/1991.
} 
geralmente reduz a accountability a uma mera avaliação impressionista do impacto da ação parlamentar sobre suas vidas. Via de regra, pessoas pertencentes aos grupos de menor capital político, como trabalhadores, mulheres, negros e minorias étnicas, são também as que revelam menor interesse pela disputa partidária, indicando a necessidade de se criar oportunidades de participação via sistema eleitoral.

Por fim, no que se refere à justificativa teórica da representação descritiva, duas questões se colocam: (i) mulheres e não-brancos terão sempre interesses, opiniões e perspectivas sociais idênticas? (ii) cotas de gênero e raça não provocariam uma perigosa segmentação da representação parlamentar, dado que relegam a segundo plano outras clivagens sociais igualmente importantes?

A resposta à primeira questão é obviamente negativa: pertencer a um grupo social não significa necessariamente expressar suas demandas. Mulheres e não-brancos podem discordar sobre quais politicas públicas aprovar e quais interesses defender. Deputadas evangélicas, por exemplo, consideram a legalização do aborto um atentado ao nascituro, enquanto as feministas, um direito ao próprio corpo. Os representantes não-brancos têm visões opostas quanto à promoção da cultura afro em regiões de maioria negra no Brasil. O candomblé é demonizado por uns e exaltado por outros.

A ideia ingênua da coincidência espontânea entre a representação descritiva e os interesses e opiniões do respectivo grupo revela falhas teóricas importantes, já que características indetitárias compartilhadas não podem ser fonte de legitimidade e controle democrático. A passagem da democracia direta para a representativa mudou definitivamente a ênfase no "quem" para no "o que" os representantes fazem e quais interesses representam. Com isso, a qualidade da representação passou a depender de mecanismos de responsabilização e prestação de contas, como os programas de governo, que vinculam as opiniões e propostas apresentadas pelos candidatos.

Com relação à segunda questão, verifica-se que, do ponto de vista político, as diferenças (homens e mulheres, negros e brancos, trabalhadores e proprietários) não podem ser consideradas características intrínsecas, mas 
estruturais, uma vez que dependem das posições que ocupam e dos papéis que exercem em dada formação social. Assim, gênero e raça são atributos estruturais, e não essenciais, que indicam distintas posição nas hierarquias sócio-politicas. Mulheres, negros e outros grupos marginalizados precisam estar presentes nos foros deliberativos e decisórios não só porque seus interesses e direitos podem ser mais bem defendidos por representantes descritivos, mas também porque a democracia necessita de "vozes diferentes" (GILLIGAN, 1982) e “perspectivas sociais" provenientes de segmentos populacionais politicamente marginalizados (YOUNG, 2000).

Com base em tais considerações, duas hipóteses são propostas:

H1: A maior ou menor efetividade da representação descritiva depende de três fatores principais: (i) "quem representa" (ii) "o que se representa" e (iii) "como pensa o representante". O primeiro fator diz respeito às categorias gênero e raça; o segundo, à representação substantiva, no sentido de que "representar significa agir no interesse dos representados, de uma forma responsiva a eles" (PITKIN, 1967, p. 226); o terceiro se relaciona à "politica de ideias" (PHILLIPS, 1995), ou seja, as crenças subjetivas e experiências de vida dos representantes e seu impacto sobre propostas de políticas públicas especificamente orientadas aos grupos marginalizados.

H2: Espera-se encontrar correlações robustas entre representação descritiva e substantiva nos casos analisados. Resta saber quais variáveis (gênero, raça e ideologia) apresentam índices de efetividade e predição de representação substantiva mais relevantes. Os resultados podem fornecer base empírica para a resposta à pergunta central da pesquisa: Quem representa os grupos marginalizados nas arenas legislativas do país?

\section{Metodologia}

Do ponto de vista empírico, esta pesquisa pretende explorar a dimensão dos interesses através de um constructo, indice de produção legislativa específica (IPLE) que mede a taxa de sucesso de proposições legislativas transformadas em leis, cujo objeto seja a defesa dos direitos e interesses de mulheres e não-brancos. As opiniões e valores foram 
operacionalizados através da variável "ideologia" medida por uma escala de sete valores; a perspectiva social é avaliada através de um cluster de variáveis extraídas de um questionário de 65 itens, das entrevistas abertas, do perfil biográfico oficial dos deputados e deputadas entrevistados, a partir dos quais foi possivel traçar a trajetória política, os tipos de capital mobilizados, bem como a atuação parlamentar de representantes descritivos e não-descritivos.

Quanto à metodologia, este estudo é essencialmente comparativo, dado que tenta descobrir diferenças relevantes entre os casos analisados, ao mesmo tempo em que generaliza os achados quando aplicável. Pretende, assim, encontrar respostas às questões suscitadas sem tomar posições a priori, ao estabelecer correlações precisas entre as variáveis, testar hipóteses e verificar os limites das generalizações implícitas aos conceitos de gênero e "raça" aplicadas ao campo político.

O período de análise compreende a 55 ${ }^{a}$ legislatura (2015-2019) da Câmara dos Deputados e de sete Assembleias Legislativas: uma no Nordeste (Bahia), três no Sudeste (Espírito Santo e Minas Gerais e Rio de Janeiro), uma no Centro-oeste (Goiás), uma no Norte (Tocantins) e uma no Sul (Paraná). Devido à considerável assimetria entre o número de deputadas e deputados, optou-se por trabalhar com uma amostra certa $(\mathrm{N}=93)$ para deputadas e uma amostra aleatória $(\mathrm{N}=207)$ para deputados (Tabela 1). ${ }^{10}$

\begin{tabular}{|c|c|c|c|c|c|c|c|}
\hline PARLAMENTO & Cadeiras & Deputados & $\%$ & Deputadas (*) & $\%$ & Deputados $(* *)$ & $\left(E^{2}\right)$ \\
\hline BAHIA (ALBA) & 63 & 56 & $89 \%$ & 7 & $11 . \%$ & 25 & $15 \%$ \\
\hline ESPÍRITO SANTO (ALES) & 30 & 26 & $87 \%$ & 4 & $13 \%$ & 17 & $15 \%$ \\
\hline PARANÁ (ALEP) & 54 & 50 & $92 \%$ & 4 & $7.5 \%$ & 23 & $15 \%$ \\
\hline MINAS GERAIS (ALMG) & 77 & 70 & $90 \%$ & 7 & $10 \%$ & 32 & $15 \%$ \\
\hline GOIÁS (ALGO) & 41 & 37 & $90 \%$ & 3 & $7.5 \%$ & 17 & $15 \%$ \\
\hline TOCANTINS (ALTO) & 24 & 21 & $87 \%$ & 3 & $12 \%$ & 10 & $15 \%$ \\
\hline RIO DE JANEIRO (ALERJ) & 70 & 60 & $85 \%$ & 10 & $14 \%$ & $29 *$ & $15 \%$ \\
\hline CÂMARA DEPUTADOS & 513 & 462 & $88 \%$ & 54 & $10 \%$ & $54 * * *$ & $15 \%$ \\
\hline TOTAL & 872 & 779 & $89 \%$ & 93 & $10 \%$ & 207 & $15 \%$ \\
\hline \multicolumn{8}{|l|}{$(*)$ Amostra certa } \\
\hline \multicolumn{8}{|c|}{$(* *)$ Amostra aleatória representativa da população. } \\
\hline \multicolumn{8}{|c|}{$(* * *)$ Amostra comparativa não-representativa da população. } \\
\hline
\end{tabular}

10 Técnica amostral para população finita (até 100.000): $n=Z^{2} \times P \times Q \times N \div E^{2} \times(N-1)+Z^{2} \times P \times Q$. Onde: $Z=$ nivel de confiança $(95 \%), P=$ quantidade de acerto esperado $(50 \%)$; $Q=$ quantidade de erro esperado (50\%); $N=$ população total; $E=$ nivel de precisão (15\%). Dado o grande número de representantes na Câmara Federal, optou-se por trabalhar com uma amostragem aleatória comparativa de 54 deputados (não representativa da população) como "grupo de controle", seguindo a proporção de 50:50 da representação de gênero. 
Como instrumento exploratório, foi elaborado, e previamente testado, um questionário impresso e padronizado (elite survey), "A Representação descritiva e substantiva de mulheres e de pessoas negras na Câmara dos Deputados e Assembleias Legislativas", contendo 65 questões fechadas.11 O questionário foi dividido em três baterias ou módulos de perguntas. $\mathrm{O}$ primeiro modulo teve por finalidade recolher dados sobre o perfil das/os respondentes: sexo, cor da pele, idade, religião, profissão, grau de escolaridade, filiação partidária, nível de representação, mandatos exercidos anteriormente e participação em comissões legislativas. Neste módulo, também foi solicitado às/aos respondentes que indicassem a sua posição ideológica numa escala de sete pontos, da "extrema esquerda" (1) à "extrema direita" (7).

A segunda bateria de questões ofereceu às/aos participantes quatro categorias de respostas ("muito importante", "importante", "pouco importante" e "sem importância") e teve como objetivo medir o grau de importância que as/os parlamentares atribuem à (i) democracia de gênero e "raça"; (ii) à cor da pele e ao gênero nas campanhas politicas; (iii) aos eleitores mulheres e negros para as suas carreiras politicas; (iv) aos critérios de contratação de assessoras/es (filiação partidária, identidade de gênero, identidade de raça e competência técnica); (v) aos meios institucionais utilizados para a promoção da democracia de gênero e "raça" (discurso em plenário, elaboração de projetos de lei, proposta de emenda à Constituição, moção de aplauso, audiência pública e comissões de inquérito). Finalmente, (vi) o grau de satisfação de cada respondente com o próprio partido, no que se refere à promoção da igualdade de gênero e "raça", foi medido por uma escala de cinco pontos, que varia de "muito satisfeito" a "muito insatisfeito".

$\mathrm{Na}$ terceira bateria de questões, quatro categorias de respostas ("concordo totalmente; concordo mais do que discordo; discordo mais do que concordo; discordo totalmente") foram oferecidas como respostas a um

\footnotetext{
11 Além do questionário, foram gravadas entrevistas semiabertas com líderes dos principais partidos representados nas diversas Casas Legislativas. Devido à limitação de espaço do presente artigo, essas entrevistas não foram incluídas na análise.
} 
conjunto de afirmações (i) cinco afirmações relacionadas com a representação de mulheres e pessoas negras na política; (ii) cinco referentes ao aperfeiçoamento da democracia de gênero e "raça"; (iv) quatro ligadas à representação de negros na política. Duas questões sobre a utilização de estratégias de campanha especificamente orientadas para atrair os votos de mulheres e negros também foram incluídas. A estas últimas, as/os respondentes foram convidadas/os a responder "sim" ou "não". O software, IBM SPSS Statistics Base, versão 22.0, foi utilizado como ferramenta de análise e o programa Excell Microsoft Office, 2016, para elaboração dos gráficos e tabelas.

Uma carta-convite, assinada pelos pesquisadores e com o timbre das instituições de fomento e pesquisa (FAPES/CAPES/UVV), na qual as/os destinatárias/os foram informadas/os dos objetivos da pesquisa e do modo de preenchimento e o envio das respostas (garantido o anonimato), foram entregues, em mãos, às/aos representantes da amostra $(\mathrm{N}=300)$ nas seguintes datas: de 27 e 30 de abril de 2015, na Assembleia Legislativa da Bahia (ALBA); de 18 a 22 de maio de 2015, na Assembleia Legislativa do Paraná (ALEP); de 8 a 12 de junho de 2015 na Assembleia Legislativa do Espírito Santo (ALES); de 16 a 20 novembro de 2015, na Assembleia Legislativa de Minas Gerais (ALMG); de 23 a 27 de novembro de 2015, na Assembleia Legislativa de Tocantins (ALTO); de 07 a 12 de dezembro de 2015, na Assembleia Legislativa de Goiás (ALGO); de 03 a 18 de maio de 2016, na Câmara dos Deputados (DF); e de 22 a 26 de maio de 2017, na Assembleia Legislativa do Rio de Janeiro (ALERJ). O tempo médio de resposta foi de 15 minutos, muito embora, em alguns casos, a/o parlamentar dedicasse mais tempo para, além das respostas, oferecer uma opinião mais detalhada sobre as questões abordadas no questionário (Tabela 2). 


\begin{tabular}{|c|c|c|c|c|}
\hline \multicolumn{4}{|c|}{ Tabela 2: Características descritivas dos participantes } & \multirow{3}{*}{$(\%)$} \\
\hline Sexo & Corda pele & $\mathbf{N}$ & $\%$ & \\
\hline \multirow[t]{5}{*}{ Mulheres } & Branca & 77 & 82,70 & \\
\hline & Parda & 9 & 9,70 & \\
\hline & Preta & 6 & 6,50 & \\
\hline & Amarela & 1 & 1,10 & \\
\hline & Total & 93 & 100,00 & \\
\hline \multirow[t]{5}{*}{ Homens } & Branca & 166 & 81,20 & \\
\hline & Parda & 31 & 15,00 & \\
\hline & Preta & 9 & 3,40 & \\
\hline & Indígena & 1 & 0,40 & \\
\hline & TOTAL & 207 & 100,00 & \\
\hline \multicolumn{5}{|c|}{ Fonte: elaboração do autor com base no perfil das/os respondentes } \\
\hline
\end{tabular}

Dado que a função primordial da representação parlamentar é legislar, foi criado um "indice de produção legislativa específica" (IPLE) como proxy de representação substantiva. Esse índice considera a taxa de sucesso ou índice de aprovação de cada proposição apresentada que efetivamente se tornou um diploma legal. Assim considerada, a representação substantiva leva em consideração apenas o "resultado" (output), e não o "processo" (procedure), que incluiria todas as propostas legislativas apresentadas, mesmo as não aprovadas. ${ }^{12}$

Segundo o Regimento Interno da Câmara dos Deputados e das Assembleias Legislativas aqui estudadas, uma proposição legislativa é toda a matéria sujeita à deliberação das respectivas casas. Os tipos de proposição considerados principais, visto que se originam nas normas descritas no art. 59 da Constituição Federal de 1988, são: Propostas de Emenda à Constituição (PEC), Projetos de Lei Complementar (PLC), Projetos de Lei Ordinária (PL), Projetos de Resolução (PRC) e Projetos de Decreto Legislativo (PDL).

O output específico da representação substantiva das/os respondentes foi operacionalizado através de uma variável contínua, "índice de produção legislativa específica" (IPLE), que é o produto do número de proposições especificas aprovadas (aquelas que normatizam as questões de gênero e

\footnotetext{
12 Os dados para elaboração do IPLE foram obtidos através de consulta dos portais oficiais das Casas Legislativas e através de informações cedidas pela Coordenação de Relacionamento, Pesquisa e Informação (CORPI) do Centro de Documentação e Informação (CEDI) da Câmara dos Deputados e das diversas Assembleias estaduais pesquisadas.
} 
"raça", como a proteção dos direitos das mulheres e a política de quotas para negros) pelo peso específico de cada tipo legislativo. ${ }^{13}$

Um espectro ideológico foi criado com base na posição autodeclarada de cada respondente, medida por uma variável ordinal de sete pontos (desde $1=$ extrema esquerda, a 7 =extrema direita). ${ }^{14}$ As tendências ideológicas dos partidos seguiram a classificação proposta por Figueiredo e Limongi (1999). ${ }^{15}$

Uma variável, designada "crença de estratificação racial" (Bailey, 2009), foi operacionalizada através da seleção de cinco itens do questionário, os quais medem as percepções das/os parlamentares quanto às possiveis causas da sub-representação política de membros de grupos marginalizados. As crenças foram classificadas em duas categorias analiticas: (i) "crenças individuais" e (ii) "crenças estruturais". A primeira enfatiza certas características obstrutivas associadas a pessoas nãobrancas; a segunda considera as assimetrias política, econômica e educacional entre brancos e não-brancos existentes no país (HANCHARD, 1999).

A variável "expectativas de representação de gênero" (BILLAND e PAIVA, 2017) avalia a percepção das/os respondentes relativamente a estereótipos e preconceitos associados à representação parlamentar de gênero. Para isso, foram selecionados nove itens do questionário.

\section{Resultados}

Os achados sinalizam uma relação significativa entre a representação substantiva, medida pelo output legislativo (IPLE), e a representação descritiva de gênero $(M=0.63)$ e racial $(M=0.41)$. Sugerem, ainda, uma atuação parlamentar comprometida com a promoção dos interesses e

\footnotetext{
13 Os pesos $(w)$ foram calculados tomando-se como base o quórum necessário para a aprovação de cada tipo de proposição: 0.60 para PEC, 0.51 para PLC e 0.25 para PL, PDL PRC. A fórmula utilizada foi $i p l e=n . w$, onde iple $=$ indice de produção legislativa específica, $n=$ total de proposições específicas aprovadas e $w=$ peso específico de cada tipo legislativo.

14 Sob uma perspectiva ideológica, os conceitos direita/esquerda remetem para valores e crenças de doutrinas politicas mais favoráveis ao igualitarismo e à mudança social (esquerda) ou à liberdade individual e ordem social (direita).

15 Com base numa pesquisa longitudinal das votações em plenário, os autores classificaram as legendas segundo padrões ideológicos clássicos. Esquerda: PSOL, PC do B, PT, PDT, PSB, PPS, PV e REDE. Centro: MDB e PSDB. Direita: DEM, PR, PP, PSD, PRP e mais uma dúzia de partidos com pouca expressão eleitoral.
} 
direitos das mulheres e das pessoas negras por parte das/os representantes descritivas/os (Tabela 3).

\begin{tabular}{|c|c|c|c|c|c|}
\hline \multicolumn{6}{|c|}{ Tabela 3: indice de Produção Legislativa Específica (IPLE) } \\
\hline Cor da pele & $\mathrm{N}$ & Min. & Max. & Média & DP \\
\hline Pessoas brancas & 243 & 0 & 3.40 & 0.310 & 0,53 \\
\hline Pessoas não-brancas & 57 & 0 & 3.80 & 0.410 & 0,66 \\
\hline \multicolumn{6}{|l|}{ Sexo } \\
\hline Masculino & 207 & 0 & 2.0 & 0.16 & 0.34 \\
\hline Feminino & 93 & 0 & 3.8 & 0.63 & 0.79 \\
\hline \multicolumn{2}{|c|}{ Elaboração do autor com base em tabulação de médias ponderadas } & & & & \\
\hline
\end{tabular}

A fim de determinar quais interesses são representados, as proposições legislativas específicas foram agrupados em dez categorias, conforme o tipo de bem jurídico tutelado (Tabela 4). Tal critério de seleção foi baseado no objeto de cada proposição legislativa aprovada pelos deputados/as amostrados. Os índices mais robustos encontrados, tanto na variável gênero ( $\mathrm{M}=0.83 /$ mulheres e $\mathrm{M}=0.21 /$ homens), como na variável "raça" $(\mathrm{M}=0.38 /$ brancos e $\mathrm{M}=0.52 /$ não-brancos $)$, são os que estão relacionados com a "violência" (Viol.), uma rubrica que agrega os diplomas legais relacionados à "Lei Maria da Penha” (Lei 11340/06).

\begin{tabular}{|c|c|c|c|c|c|c|c|c|c|c|}
\hline \multicolumn{11}{|c|}{ Tabela 4: Tutela jurídica contemplada em lei (valor médio-ponderado) } \\
\hline & Viol. & Edu. & Dir. Tra. & U.P. & Prev. Soc. & Ação A. & Dir. Hum. & Parida. & Saúde & Dia Nac. \\
\hline \multicolumn{11}{|l|}{ Fem. } \\
\hline $\mathrm{N}$ & 93 & 93 & 93 & 93 & 93 & 93 & 93 & 93 & 93 & 93 \\
\hline Média & 0,83 & 0,24 & 0,18 & 0,1 & 0,11 & 0,28 & 0,3 & 0,27 & 0,11 & 0,07 \\
\hline DP & 1,05 & 0,53 & 0,47 & 0,3 & 0,44 & 0,57 & 0,73 & 0,61 & 0,38 & 0,26 \\
\hline Total & 69 & 20 & 15 & 8 & 9 & 23 & 25 & 22 & 9 & 6 \\
\hline \multicolumn{11}{|l|}{ Masc. } \\
\hline $\mathrm{N}$ & 207 & 207 & 207 & 207 & 207 & 207 & 207 & 207 & 207 & 207 \\
\hline Média & 0,21 & 0,06 & 0,07 & 0,07 & 0,04 & 0,07 & 0,1 & 0,01 & 0,02 & 0 \\
\hline DP & 0,54 & 0,26 & 0,26 & 0,26 & 0,21 & 0,29 & 0,36 & 0,11 & 0,15 & 0,02 \\
\hline Total & 38 & 11 & 13 & 13 & 8 & 12 & 17 & 2 & 4 & 0,25 \\
\hline \multicolumn{11}{|c|}{ Não brancos } \\
\hline $\mathrm{N}$ & 57 & 57 & 57 & 57 & 57 & 57 & 57 & 57 & 57 & 57 \\
\hline Média & 0.52 & 0,04 & 0,08 & 0,06 & 0,06 & 0,26 & 0,22 & 0,12 & 0,06 & 0,04 \\
\hline DP & 1,01 & 0,2 & 0,27 & 0,23 & 0,23 & 0,56 & 0,61 & 0,52 & 0,31 & 0,19 \\
\hline Total & 26 & 2 & 4 & 3 & 3 & 13 & 11 & 6 & 3 & 2 \\
\hline \multicolumn{11}{|l|}{ Brancos } \\
\hline $\mathrm{N}$ & 243 & 243 & 243 & 243 & 243 & 243 & 243 & 243 & 243 & 243 \\
\hline Média & 0,38 & 0,14 & 0,11 & 0,84 & 0,06 & 0,14 & 0,14 & 0,08 & 0,04 & 0,02 \\
\hline$D P$ & 0,73 & 0,41 & 0,35 & 0,27 & 0,31 & 0,36 & 0,48 & 0,32 & 0,23 & 0,13 \\
\hline Total & 81 & 29 & 24 & 18 & 14 & 22 & 31 & 18 & 10 & 4 \\
\hline
\end{tabular}


O segundo índice de produção legislativa mais significativo, sobre "Direitos Humanos" [Dir. Hum.] (M=0.30/mulheres; $M=0.10 /$ homens; $\mathrm{M}=0.14$ /brancos e $\mathrm{M}=0.22$ / não-brancos), distingue-se do anterior ("Violência") por reunir leis cujo foco principal é a proteção dos direitos básicos de grupos marginalizados (indios e negros), apenados, pessoas idosas, crianças e outros grupos sociais vulneráveis.

$\mathrm{O}$ indice "Ação afirmativa" [Ação A.] (M=0.28/mulheres; $\mathrm{M}=0.7 /$ homens; $\mathrm{M}=0.14 /$ branco e $\mathrm{M}=0.26$ / não-brancos) reúne os diplomas legais contento medidas compulsórias que combatem a discriminação de gênero e "raça" por meio da promoção da igualdade de oportunidades.

$\mathrm{O}$ indice "Paridade" [Parida.] ( $\mathrm{M}=0.27 /$ mulheres; $\mathrm{M}=0.01 /$ homens; $\mathrm{M}=0.08$ /brancos e $\mathrm{M}=0.12$ / não-brancos) indica medidas que visam dar efetividade ao "princípio de paridade" entre os sexos, estabelecido no Artigo $5^{\circ}$, Inciso I, Constituição de 1988. Reunidas nesta rubrica encontram-se ações corretivas, não compulsórias, que visam garantir a igualdade de oportunidades e tratamento, como, por exemplo, incentivos fiscais às empresas que adotam quotas de género e "raça" nos seus quadros.

O "Dia Nacional" [Dia Nac.] ( $\mathrm{M}=0,07 /$ mulheres; $\mathrm{M}=0.00 /$ homens; $\mathrm{M}=0.02$ /brancos e $\mathrm{M}=0.04$ / não-brancos) elenca todas as leis que estabelecem datas comemorativas de mulheres e negros que, de algum modo, se destacaram na luta pela igualdade de gênero e "raça" na história do país.

$\mathrm{O}$ indice "Utilidade Pública" [U.P.] (M=0.10/mulheres; $\mathrm{M}=0.47 /$ homens; $\mathrm{M}=0.57 /$ branco e $\mathrm{M}=0.6 /$ não-brancos) abriga leis ordinárias que declaram de utilidade pública instituições ou organizações, sem fins lucrativos, criadas para prestar assistência educacional, cultural ou econômica às mulheres ou negros em situações de vulnerabilidade social.

$O$ indice "Educação" [Edu.] ( $M=0.24 /$ mulheres; $M=0.06 /$ homens; $\mathrm{M}=0.14$ /branco e $\mathrm{M}=0.04$ / não-brancos) refere-se às leis que, de algum modo, promovem o ensino de valores ético-morais para prevenir e erradicar toda e qualquer forma de violência e discriminação de género ou racial.

O "Direito Trabalhista" [Dir. Trab.] (M=0.18/mulheres; $\mathrm{M}=0.07 /$ homens; $\mathrm{M}=0.11 /$ branco e $\mathrm{M}=0.08 /$ negro) reúne as medidas legais, 
no âmbito das Convenções da Organização Mundial do Trabalho (OIT), que dispõem sobre a proteção às mulheres e a igualdade de gênero, das quais seis foram ratificadas pelo Brasil. Inclui, dentre outras, a proibição do trabalho análogo à escravatura, a proteção à maternidade, regulamentação do trabalho noturno e subterrâneo de mulheres e igualdade de remuneração.

$O$ indice "Previdência social" [Prev. Soc.] (M=0.11/mulheres; $\mathrm{M}=0.04$ /homens; $\mathrm{M}=0.06$ /branco $\mathrm{M}=0.06$ / não-brancos) elenca diplomas legais que visam incentivar a formalização do emprego e da segurança social, sobretudo de mulheres negras, $66 \%$ das quais trabalham sem o competente registro na Carteira de Trabalho (IBGE, 2016).

$\mathrm{O}$ indice "Saúde" $(\mathrm{M}=0.11 /$ mulheres; $\mathrm{M}=0.02 /$ homens; $\mathrm{M}=0.04$ /branco $\mathrm{M}=0.06$ / não-brancos) inclui o amparo legal aos direitos das mulheres no âmbito da saúde, como o atendimento prioritário à gestante, o acompanhamento durante o parto e a reconstrução de mama, entre outros.

Tais resultados contrastam com os constrangimentos institucionais que iniciativas de parlamentares encontram na tramitação e aprovação de diplomas legais no processo legislativo pátrio. Isso porque o Executivo, seja federal ou estadual, possui meios eficazes de controle da agenda legislativa, resultando daí a baixa taxa de sucesso de proposições apresentadas por deputados e deputadas. Em sentido contrário, o Executivo raramente é derrotado, além de ser responsável pela maioria das iniciativas que se tornam lei, o que se reflete em uma alta taxa de dominância. Já o Legislativo, porque age somente após o Executivo ter feito a proposta, tem seu raio de ação limitado: além de aprovar ou rejeitar as propostas do Executivo, aos Membros do Parlamento resta a simbólica tarefa de apresentar projetos de pouco impacto social, como a criação de datas comemorativas ou a declaração de utilidade pública de instituições beneficentes locais (FIGUEIREDO e LIMONGI, 2000).

Uma possível explicação para o relativo sucesso da representação substantiva de gênero e "raça" em nossos Parlamentos se deve ao fato de que os bens jurídicos tutelados ocorrem em um contexto sociocultural 
marcado pela violência física e simbólica extrema, responsável pela vitimização cotidiana de mulheres e pessoas negras nos grandes centros urbanos do país. Graças às medidas protetivas aprovadas, como a Lei Maria da Penha e a tipificação do feminicídio e do racismo, é que algum progresso tem sido alcançado, embora ainda distante de qualquer padrão civilizatório minimo.

\section{I Filiação ideológico-partidária}

Os partidos políticos são frequentemente mobilizados como variáveis independentes em modelos teóricos os mais diversos: políticas públicas, ciclos de gastos públicos, desempenho dos governos, resultados macroeconômicos, coligações, comportamento do eleitor, atuação parlamentar, governabilidade. Entretanto, um dos principais aspectos do impacto dos partidos sobre outras variáveis está em franca decadência: a ideologia. Como em todo o mundo, as distâncias entre as posições dos partidos na dimensão esquerda-direita vêm se reduzindo e muitas análises têm reportado efeito não significativo desta variável. Além disso, os partidos políticos brasileiros são invariavelmente acusados de desviarem-se das funções que supostamente deveriam cumprir, tais como a representação e canalização das demandas provenientes da sociedade.

Contudo, existem indicadores de que a democracia brasileira, cuja consolidação parece não haver dúvidas, funciona em bases partidárias: são os partidos que selecionam as elites políticas e formam o legislativo e o governo. A transformação no papel que os partidos exercem nas democracias já foi descrita e teorizada por vários autores, mas no Brasil parece não ter sido bem acolhida. Exemplo disso é a reiterada denúncia da ausência de vínculos societários, que seria responsável pela alegada instabilidade do sistema partidário brasileiro. Abordagens teóricas como a dos "partidos cartéis", por exemplo, que se afastam das concepções clássicas, têm aparecido nas análises do arranjo institucional brasileiro, especialmente no que se refere às relações entre executivo e legislativo. Mas nos estudos específicos da área de partidos políticos, raramente se 
encontram referências que superem a inovação que o conceito de partido catch all representou nos anos sessenta do século XX.

A discussão que se propõe aqui parte do pressuposto de que conhecer as preferências politicas dos partidos brasileiros é importante para compreender o funcionamento do sistema partidário e todas aquelas demais variáveis dependentes citadas acima. Trata-se de identificar o conteúdo das preferências políticas dos partidos e de acessá-las analiticamente em um contexto de esmorecimento das diferenças ideológicas. Para isso, é necessário lançar mão de recursos teóricos e metodológicos inovadores, que superem os impasses gerados pela crise de representatividade dos partidos. Ao mesmo tempo em que parece não haver controvérsia quanto à ordenação dos partidos brasileiros no eixo esquerda-direita, a sua identidade política é reiteradamente posta em dúvida, seja pela imprensa, seja por analistas acadêmicos, ou ainda nos resultados das pesquisas de opinião pública. Parece haver um descompasso entre a validade do ainda persistente uso da ideologia partidária como variável explicativa (em análises de resultados eleitorais, coligações, políticas públicas) e o diagnóstico corrente de inconsistência ideológica dos partidos brasileiros.

As análises que mobilizam ideologia partidária quase invariavelmente classificam PT e PDT na esquerda, PMDB e PSDB no centro e $\mathrm{PDS} / \mathrm{PPR} / \mathrm{PPB} / \mathrm{PP}$, PTB e PFL/DEM na direita. As demais incluem avaliação de especialistas (acadêmicos ou da imprensa), percepção da opinião pública, comportamento parlamentar e autodeclaração dos políticos.

Classificar os partidos politicos brasileiros de acordo com seu espectro ideológico não é uma tarefa fácil, e esta discussão fugiria ao escopo deste trabalho. No entanto, optou-se por utilizar a classificação de Mainwaring, Meneguello e Power (2000), e, para os partidos com gênese posterior ao ano 2000, a classificação elaborada por Krause, Dantas e Miguel (2010). Segundo Mainwaring, Meneguello e Power (2000, p. 93), embora haja particularidades no processo de institucionalização dos partidos brasileiros, é possivel observar uma diferenciação programática, pois os partidos demonstraram posições distintas quanto a questões políticas, econômicas, 
sociais e morais, de modo que o comportamento no Congresso Nacional pode ser analisado através de algumas clivagens na escala esquerda- direita. Krause, Dantas e Miguel (2010) classificam as legendas a partir da origem do partido, origem das lideranças partidárias, e o posicionamento das bancadas no Congresso Nacional. O quadro abaixo apresenta uma síntese desta classificação. 


\section{Gráfico 1: espectro ideológico dos partidos políticos}

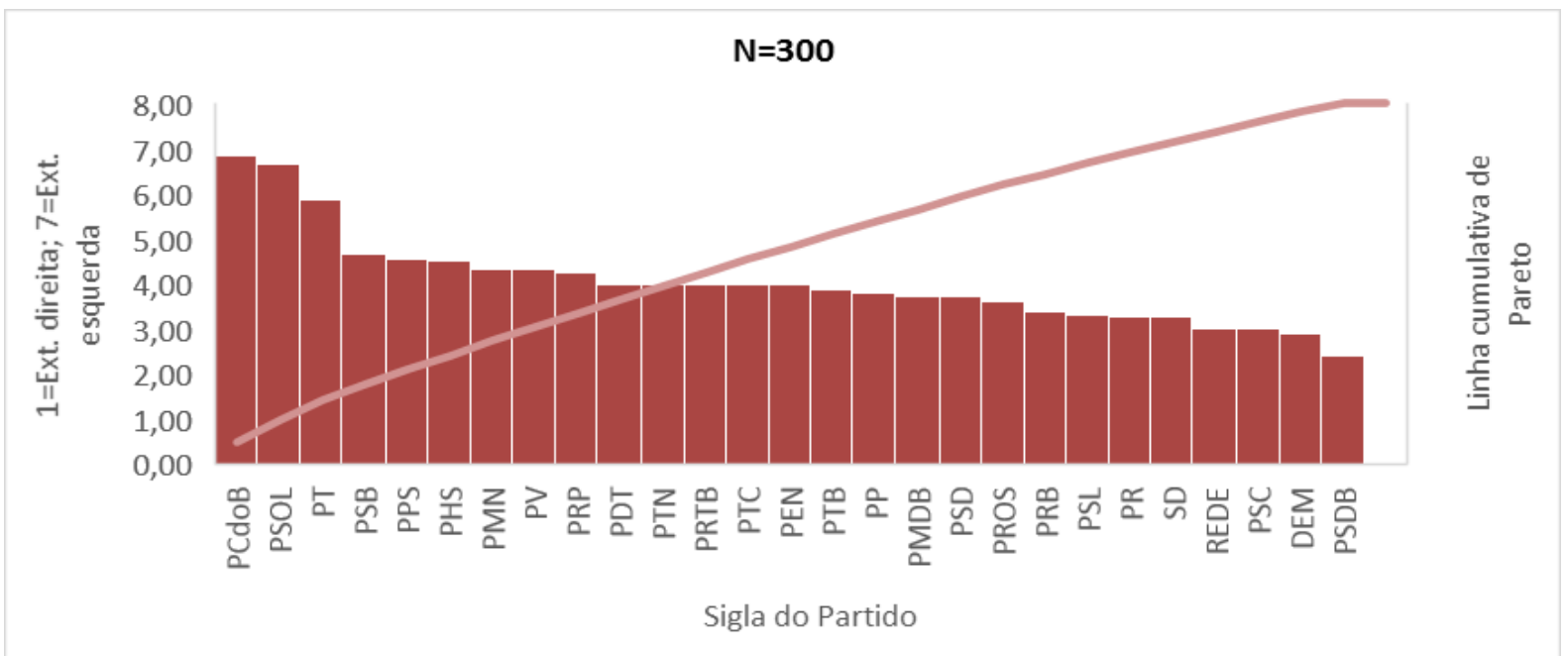

Fonte: Elaboração do autor com base em Mainwaring, Meneguello \& Power (2000).

$\mathrm{Na}$ amostra, 27 partidos estão representados. As mulheres foram eleitas por 22 agremiações e os homens por 25 delas, o que confirma a tendência de as mulheres serem eleitas num número mais concentrado de partidos, quando comparadas com os homens (ARAÚJO, 2001). A amostra também indica uma tendência das mulheres a se filiarem a partidos de esquerda (28.9\%), como o Partido dos Trabalhadores (PT, 19.3\%) e o Partido Comunista do Brasil ( $\mathrm{PC}$ do $\mathrm{B}, 9.6 \%$ ), que adotam políticas internas mais democráticas em relação à representação de mulheres.

Este resultado confirma uma tendência registrada nas democracias consolidadas de que, quanto mais à esquerda do espectro ideológico se posiciona um partido, mais atrai mulheres, negros e outros grupos marginalizados. Tal tendência tem uma clara explicação histórica no fato de que foram os partidos de esquerda os primeiros a incluir algum tipo de norma interna promotora de uma maior participação de mulheres e negros nos seus quadros. 
Gráfico 1: Gênero e Ideologia $(\mathrm{N}=300)$

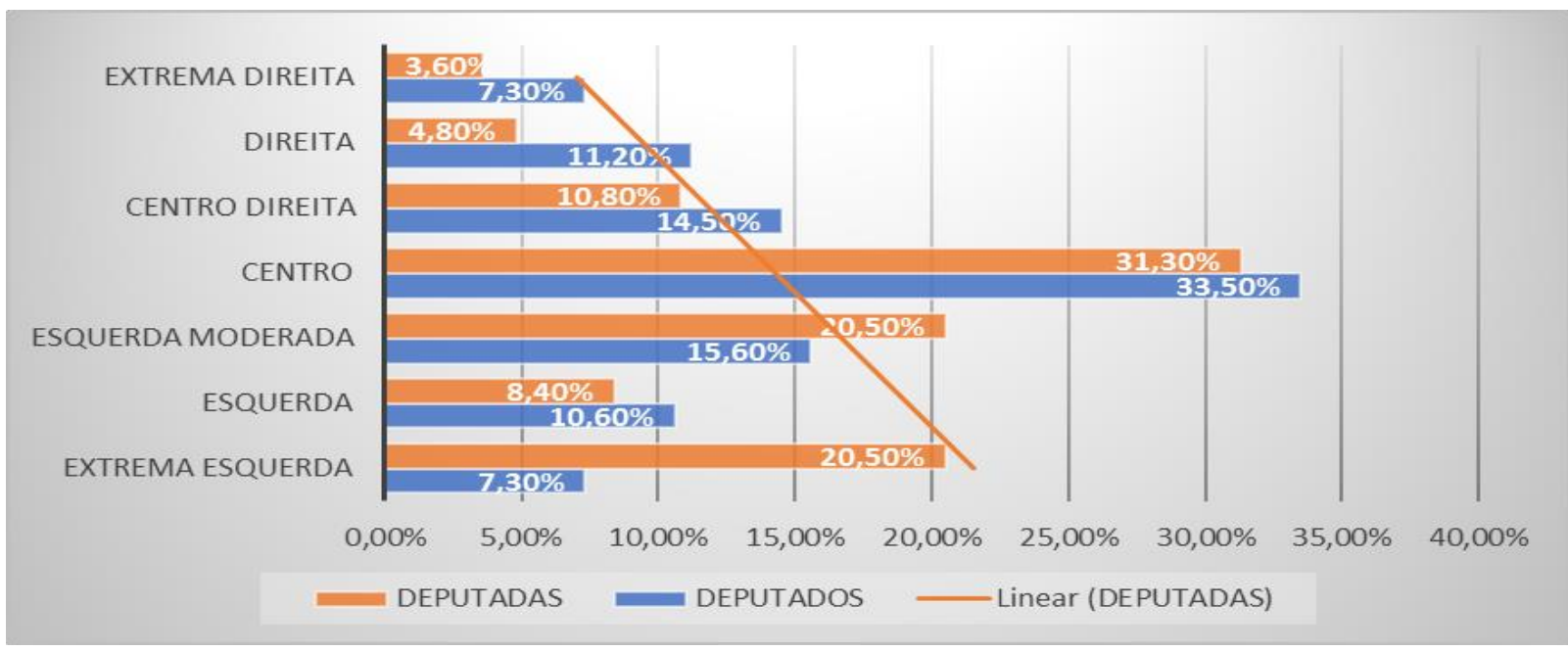

Fonte: Elaboração do autor com base no espectro ideológico autodeclarado dos entrevistados.

Os resultados também revelam uma relativa consistência ideológicaprogramática das/os respondentes, considerando-se o cruzamento do espectro ideológico autodeclarado e o partidário (Gráficos 1 e 2): os partidos tradicionalmente de esquerda -- como o Partido dos Trabalhadores (PT), o Partido Socialismo e Liberdade (PSOL) e o Partido Comunista do Brasil (PC do B) -- reúnem elevadas porcentagens na escala ideológica, enquanto os partidos historicamente identificados com o centro-direita, como o Partido do Movimento Democrático Brasileiro (PMDB), o Partido da Social Democracia Brasileira (PSDB) e o Democratas (DEM), exibem valores médios ou baixos da referida escala. Estes resultados são compativeis com as pesquisas de Figueiredo e Limongi (1998 e 1999). 


\section{Gráfico 2: cor da pele e ideologia}

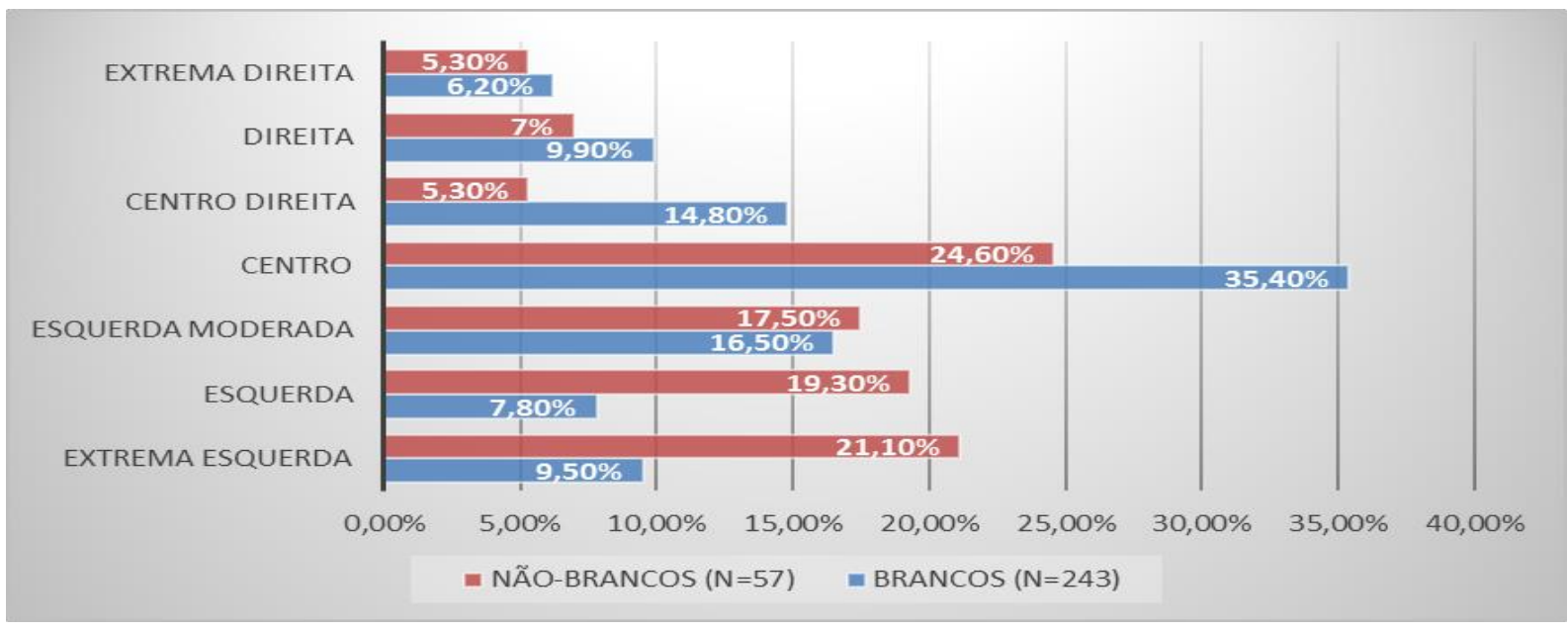

Fonte: elaboração do autor com base no espectro ideológico autodeclarado dos entrevistados.

Segundo os autores, os alinhamentos majoritários e a disciplina partidária correspondem aos cortes clássicos entre esquerda e direita. No entanto, essa tendência verifica-se num quadro de polarização mais pronunciada entre "direita e esquerda", no qual pequenos partidos de extrema-esquerda, como o Partido Comunista do Brasil (PCdoB), exibem um indice considerável de representantes negros/as, o que sugere um maior compromisso ideológico com setores sociais historicamente excluídos da politica.

Tais alinhamentos reproduzem o desenho ideológico das coligações eleitorais, ainda que não signifiquem organicidade ou fidelidade partidária e prática legislativa colegiada. Segundo Novaes (1994), “as estruturas partidárias são frágeis, mas as afinidades ideológicas conformam campos estáveis" (p. 114).

\subsection{Crenças de estratificação racial}

A análise fatorial (Tabela 5), aplicada para explorar as possiveis correlações entre os itens selecionados do questionário e determinar os fatores latentes às variáveis em questão, utilizou um autovalor de 1.0 como ponto de corte para a identificação dos fatores estatisticamente relevantes. A matriz rotativa de componentes sofreu uma rotação Varimax ortogonal 
padrão e o critério de normalização de Kaiser foi aplicado (KMO $=0.610$ e Bartlett's $=273,916 ; \mathrm{df}=10$; sig. $=.000)$. A análise foi realizada para toda a amostra $(\mathrm{N}=300)$ e dois fatores responsáveis por $70 \%$ da variância foram encontrados: o fator 1, responsável por $42.5 \%$ da variância, foi denominado "causas estruturais" e o fator 2, responsável por $27.5 \%$ da variância, foi designado por "causas individuais". A nomeação de tais fatores encontra suporte na literatura (SWAIN, 1993; WINANT, 1999; SANSONE, 2003).

\begin{tabular}{|l|c|c|}
\hline $\begin{array}{l}\text { Tabela 5: Análise Fatorial - crenças de } \\
\text { estratificação racial (N=300) }\end{array}$ & $\begin{array}{c}\text { Crenças } \\
\text { estruturais }\end{array}$ & $\begin{array}{c}\text { Crenças } \\
\text { individuais }\end{array}$ \\
\hline $\begin{array}{l}\text { “A ordenação hierárquica de acordo com a brancura da pele } \\
\text { prejudica a candidatura de mulheres e de pessoas negras”. }\end{array}$ & $\mathbf{0 . 8 2 0}$ & -0.032 \\
\hline $\begin{array}{l}\text { “As quotas eleitorais favorecem a candidatura de mulheres e } \\
\text { pessoas negras”. }\end{array}$ & $\mathbf{0 . 8 1 2}$ & -0.098 \\
\hline $\begin{array}{l}\text { “Os partidos políticos tradicionais dão preferência à } \\
\text { candidatura de pessoas brancas”. }\end{array}$ & $\mathbf{0 . 8 0 4}$ & -0.078 \\
\hline $\begin{array}{l}\text { “O eleitorado negro privilegia mais o estatuto } \\
\text { socioeconômico das/dos candidatas/os e menos a } \\
\text { identidade étnica”. }\end{array}$ & -0.064 & $\mathbf{0 . 8 6 7}$ \\
\hline $\begin{array}{l}\text { “A estratégia eleitoral baseada na identidade étnica sempre } \\
\text { fracassou no Brasil”. }\end{array}$ & -0.083 & $\mathbf{0 . 8 6 2}$ \\
\hline $\begin{array}{l}\text { (*) Método de extração: análise de componentes principais } \\
\text { (**) Método de rotação: Varimax com normalização Kaiser }\end{array}$ & & \\
\hline
\end{tabular}

Fonte: Elaboração do autor com base no survey.

Os resultados apresentados mostram cargas fatoriais bastante elevadas $(>0.80)$ para as três primeiras crenças estruturais e para as duas últimas crenças individuais. Os valores negativos revelam que as percepções são mutuamente exclusivas, isto é, aquelas/es que concordam com crenças estruturais discordam das crenças individuais e vice-versa. Desse modo, a ideia de que as assimetrias de representação política seguem a lógica do espectro de cor da pele, desfavorecendo os/as candidatos/as no polo mais negro desse espectro, encontrou uma elevada carga fatorial no componente "crenças estruturais" (0.820 e 0.804) e relativa discordância no componente “crenças individuais" (-0.032 e -0.078), isto é, entre as/os respondentes que 
negam a relevância do fator racial na política. Essa mesma crença individualista atribui à variável "classe ou estatuto socioeconômico" preeminência sobre as variáveis de estratificação racial (0.867), assim como se mostra descrente nas estratégias eleitorais baseadas na identidade racial (0.862).

\subsection{Expectativas de representação de gênero}

Outra análise fatorial (AF) foi aplicada para explorar possiveis correlações entre os itens selecionados e determinar fatores latentes às variáveis em questão (Tabela 6). Foi igualmente utilizado um autovalor de 1.0 como ponto de corte para a identificação dos fatores estatisticamente relevantes. A matriz rotativa de componentes sofreu uma rotação Varimax ortogonal padrão e o critério de normalização de Kaiser foi aplicado (KMO = 0.859 e Bartlett's $=968.732 ; \mathrm{df}=36 ;$ sig. $=.000)$.

A análise foi realizada para toda a amostra $(\mathrm{N}=300)$ e dois fatores responsáveis por $62 \%$ das variações foram encontrados: o fator 1 , responsável por $47 \%$ da variância, foi denominado "expectativas estruturais", por agregar cargas fatoriais elevadas no que se refere às questões institucionais. O fator 2 , responsável por $15 \%$ da variância, foi classificado como "expectativas individuais", por agregar cargas fatoriais insignificantes no que se refere às questões estruturais/institucionais e cargas expressivas relativamente às questões individuais. A nomeação de tais fatores foi proposta com base na literatura (Aalberg e Jessen, 2007, Billand e Paiva, 2017).

$\mathrm{Na}$ coluna "expectativa estruturais", os resultados apontam cargas fatoriais elevadas para "preconceitos" (0.864) e “estereótipos" (0.806) de gênero como fatores prejudiciais à candidatura de mulheres e cargas fatoriais insignificantes na coluna "expectativas individuais" (0.140 e 0.242), sugerindo percepções dicotômicas em relação à representação de gênero por parte das/os respondentes. Tal dicotomia é ainda reforçada quando consideramos os elevados valores positivos no item "importância das 
questões de gênero na atuação parlamentar" (0.718) e negativos na questão “politica não atrai mulheres" (-0.748).

\begin{tabular}{|l|c|c|}
\hline $\begin{array}{l}\text { Tabela 6: expectativas de representação de gênero } \\
\text { (N=300). }\end{array}$ & $\begin{array}{c}\text { Expectativas } \\
\text { estruturais }\end{array}$ & $\begin{array}{c}\text { Expectativas } \\
\text { individuais }\end{array}$ \\
\hline $\begin{array}{l}\text { "Preconceitos de gênero prejudicam a candidatura de } \\
\text { mulheres". }\end{array}$ & $\mathbf{0 , 8 6 4}$ & 0,14 \\
\hline $\begin{array}{l}\text { "Estereótipos de gênero prejudicam a candidatura de } \\
\text { mulheres". }\end{array}$ & $\mathbf{0 , 8 0 6}$ & 0,242 \\
\hline $\begin{array}{l}\text { As lideranças partidárias não favorecem a candidatura } \\
\text { de mulheres". }\end{array}$ & $\mathbf{0 , 7 8 4}$ & 0,134 \\
\hline "Sou a favor das quotas eleitorais para mulheres". & $\mathbf{0 , 7 3 6}$ & 0,267 \\
\hline $\begin{array}{l}\text { "Sou a favor das quotas de cadeiras no Parlamento para } \\
\text { mulheres". }\end{array}$ & $\mathbf{0 , 7 2 2}$ & 0,146 \\
\hline $\begin{array}{l}\text { "Os partidos usam a tática de candidaturas 'laranja' de } \\
\text { mulheres apenas para cumprir a obrigação legal". }\end{array}$ & $\mathbf{0 , 6 8 3}$ & $-0,369$ \\
\hline "A política não atrai as mulheres". & 0,055 & $\mathbf{- 0 , 7 4 8}$ \\
\hline $\begin{array}{l}\text { "As questões de gênero são importantes para minha } \\
\text { atuação parlamentar". }\end{array}$ & 0,309 & $\mathbf{0 , 7 1 8}$ \\
\hline $\begin{array}{l}\text { "As questões ligadas à democracia de gênero são } \\
\text { importantes para minha atuação parlamentar". }\end{array}$ & 0,5 & 0,518 \\
\hline Método de Extração (AF): componentes principais. & & \\
\hline $\begin{array}{l}\text { Método de Rotação (AF): Varimax com normalização } \\
\text { Kaiser. }\end{array}$ & & \\
\hline
\end{tabular}

Samuel Popkin (1991) define os “estereótipos", no campo políticoeleitoral, por atalhos cognitivos" ou "atalhos informacionais" que visam tanto reduzir a complexidade das informações geradas pelo campo político, como facilitar a escolha das/os eleitoras/es. Assim, os cidadãos e cidadãs podem usar diferentes "estereótipos" para avaliar as características individuais de uma candidata/o, como a filiação partidária, os traços demográficos, a cor da pele e o gênero. Segundo o autor, se a filiação partidária é um atalho informacional "positivo" para a avaliação das/os concorrentes, os estereótipos de gênero podem ser enganosos e produzir um "impacto negativo" na disputa eleitoral. 
Em relação ao papel negativo das lideranças partidárias na promoção das candidaturas femininas (escores 0.784), os resultados confirmam a percepção generalizada entre as/os parlamentares de que as dificuldades se verificam já no processo de socialização pré-eleitoral. Mesmo nas legendas programaticamente "comprometidas" com a causa feminista, esta pesquisa revelou que as lideranças partidárias, tradicionalmente dominadas por homens brancos, discriminam as mulheres de várias formas.

No que respeita à questão "a política não atrai as mulheres", uma carga fatorial negativa foi encontrada na coluna "expectativas individuais" (0.748), indicando discordância com a afirmação que contrasta com os elevados valores positivos no item "importância das questões de gênero na atuação parlamentar" (0.718). Esses resultados sugerem que os/as representantes alinhados/as com as "expectativas individuais", embora descrentes do real impacto dos fatores "estruturais" sobre a própria carreira política, não deixam de conferir importância às questões de gênero, assim como de acreditar na vocação política das mulheres, a exemplo do próprio sucesso eleitoral.

No Brasil, a indicação de mulheres candidatas, na esmagadora maioria dos casos, é meramente "proforma", isto é, serve apenas para atender aos requisitos legais. Os partidos, simplesmente, não investem, não incentivam, nem levam a sério as candidaturas de mulheres. Muitos nem sequer chegam aos $30 \%$ previstos na lei. Tal fenómeno, geralmente, designado por "candidaturas laranjas", apresentou uma carga fatorial de 0.683 na nossa análise.

No entanto, seria precipitado concluir que a politica de cotas eleitorais é ineficiente em si mesma. É preciso avaliar os resultados de tal política de acordo com cada contexto eleitoral e momento político específicos. Se a institucionalização das quotas serviu para incrementar a representação das mulheres em alguns países, como em Portugal e na Argentina (WÄNGNERRUND, 2009; SANTOS e ESPÍRITO-SANTO, 2017), noutros ela enfrenta barreiras político-estruturais que condicionam negativamente seus resultados, como é o caso do Brasil (SACCHET, 2008, FRANCESCHET et al., 
2012). Ainda que generalizações possam ser feitas sobre as quotas como projeto político, não se pode fazer o mesmo sobre os seus resultados. Tal é a percepção das/os respondentes quando avaliam favoravelmente, tanto as cotas eleitorais (0.736), como as quotas de cadeiras para mulheres (0.722).

\subsection{Ideologia e produção legislativa}

A correlação entre a variável categórica "espectro ideológico" (ideologia) e o "indice de produção legislativa específica" (IPLE) confirmou a importância crucial da "política de ideias" descrita por Phillips (1995) como preditor de representação substantiva. Os resultados mostram que a soma das médias das/dos representantes alinhadas/os ao espectro ideológico da esquerda (extrema esquerda, esquerda e centro-esquerda) equivale a $M=1.95$. Isso representa um escore sete vezes maior do que às médias referentes aos representantes situados ao centro-direita do espectro ideológico, cujo escore é apenas de $\mathrm{M}=0.27$. Assim, a variável "ideologia" aparece nos resultados como um fator determinante de produção legislativa e representação substantiva (Tabela 7).

Tabela 7: ideologia e produção legislativa (IPLE)

\begin{tabular}{|c|c|c|c|c|c|c|}
\hline $\begin{array}{c}\text { Extrema- } \\
\text { esquerda }\end{array}$ & Esquerda & $\begin{array}{c}\text { Centro- } \\
\text { esquerda }\end{array}$ & Centro & $\begin{array}{c}\text { Centro- } \\
\text { direita }\end{array}$ & Direita & $\begin{array}{c}\text { Extrema- } \\
\text { direita }\end{array}$ \\
\hline Média & Média & Média & Média & Média & Média & Média \\
\hline 0,78 & 0,68 & 0,49 & 0,18 & 0,05 & 0,04 & 0 \\
\hline
\end{tabular}

Fonte: elaboração do autor com base em médias ponderadas.

Tal hipótese foi confirmada por uma regressão logística binária entre a variável dicotômica "gênero" (homem=0, mulher=1) e a variável contínua "indice de produção legislativa" (IPLE) como proxy de representação substantiva. A medida de intensidade de associação encontrada $(\operatorname{Exp}(B)=$ $5,497)$ mostra que as deputadas têm 544\% mais chances de propor e aprovar uma lei especificamente voltada para proteção de mulheres e negros do que os deputados (Tabela 8) ${ }^{16}$.

\footnotetext{
16 Para um intervalo de confiança de 95\%, a conversão do $\operatorname{Exp}(\mathrm{B})$ em porcentagem $(\mathrm{P})$ segue a fórmula: $\mathrm{P}=100 \mathrm{x}(\operatorname{Exp}(\mathrm{B})-1)$.
} 
Aplicando-se o mesmo modelo para se medir a razão de chances entre a variável dicotômica "ideologia" ( $1=$ esquerda, $0=$ direita $)^{17}$ e a produção legislativa específica (IPLE), chega-se a $\operatorname{Exp}(B)=14,149$ o que, em porcentagem, significa que um/a representante da esquerda (homem ou mulher) tem uma probabilidade $1300 \%$ maior de propor e aprovar uma lei que promove a democracia de gênero e "raça" do que um/a representante da direita. E a correlação entre "raça" e produção legislativa é de $\operatorname{Exp}(B) 1,355$, isto é, uma/um representante não-branca/o apresenta 35,5\% de chances de aprovar uma lei em favor de pessoas negras do que uma/um representante branca/o (Tabela 8).

Fonte: Tabela 8: gênero e ideologia como preditores de produção legislativa (IPLE)

\begin{tabular}{|c|c|c|c|c|c|c|}
\hline & \multicolumn{3}{|c|}{ Gênero } & & & \\
\hline IPLE & B & S.E. & Wald & df & Sig. & Exp(B) \\
\hline Constante & $-1,704$ & 0,305 & 31,304 & 1 & 0 & $\mathbf{5 , 4 9 7}$ \\
\hline & & 0,165 & 68,33 & 1 & 0 & 0,255 \\
\hline IPLE & B & S.E. & Wald & df & Sig. & Exp(B) \\
\hline Constante & $-1,554$ & 0,171 & 82,39 & 1 & 0 & 0,211 \\
\hline & & & Ideologia & & & \\
\hline IPLE & B & S.E. & Wald & df & Sig. & Exp(B) \\
\hline Constante & $-1,216$ & 0,163 & 55,391 & 1 & 0 & 0,296 \\
\hline
\end{tabular}

Fonte: Elaboração do autor com base na regressão logística binária.

\section{Conclusão}

A representação descritiva e substantiva de mulheres e pessoas negras nas Casas Legislativas aqui analisadas remete para discussões teóricas acaloradas sobre qual seria o papel da democracia representativa no Brasil. De um lado, as/os defensoras/es da tese da "desconexão" (PITKIN, 1967) argumentam que o âmbito da representação política é antes de mais a defesa dos direitos e a promoção dos interesses substantivos das/os representadas/os por meio das funções deliberativas e agregativas.

\footnotetext{
17 A variável dicotômica "esquerda" (=1) agrega os valores do espectro ideológico referentes a "extrema esquerda, esquerda e centro-esquerda", enquanto a variável "direita" $(=0)$ reúne os valores referentes à "extrema-direita, direita, centro-direita e centro".
} 
Por outras palavras, nesta perspectiva, o fazer (representação substantiva) precede o ser (representação descritiva).

De outro lado, argumenta-se, a democracia pressupõe a representação de uma "pluralidade de perspectivas" e de interesses nas esferas de representação. Nesse sentido, a inclusão de mulheres e pessoas negras na politica seria uma condição sine qua non da representatividade democrática, dado que os próprios processos deliberativos pressuporiam a manifestação de diferentes perspectivas e interesses de variados grupos. O mesmo ocorreria com os processos agregativos, os quais, ao buscarem equiparar e balancear interesses em conflito, seriam mais bem servidos por representantes descritivas/os, uma vez que as pessoas e os grupos sociais tendem a conhecer melhor seus próprios interesses e experiências.

Sabe-se que as ideias dos deputados e deputadas não estão de todo dissociadas das suas vivências materiais, psicológicas e sociais. É por isso que uma composição mais plural dos espaços político-decisórios propiciaria a expressão de diferentes perspectivas. Tal favoreceria politicas voltadas para interesses e necessidades sociais mais amplas e impediria que a exclusão de tais perspectivas tornasse invisiveis questões e demandas pertinentes a grupos sociais historicamente alijados da politica.

Os resultados desta pesquisa fornecem suporte empírico à relação entre a representação descritiva e substantiva de mulheres e pessoas negras nos casos aqui analisados. Foram encontrados índices significativamente maiores de produção legislativa específica entre as/os representantes descritivas/os (mulheres e não-brancos), o que sugere uma atuação parlamentar "comprometida" com a promoção da democracia de gênero e de "raça". Não obstante, a ideologia aparece como forte preditora da representação substantiva, superando largamente as variáveis descritivas. Um forte indicativo de que a visão de mundo das deputadas e deputados, suas opiniões e ideias, influenciam mais o seu comportamento do que suas características descritivas.

Apesar da prevalência do fator "ideologia", pode-se afirmar que a representação descritiva é um imperativo normativo e empírico da democracia no Brasil. Normativo, porque as noções tanto de um indivíduo 
abstrato e de um bem comum impermeável às diferenças individuais são incompativeis com a realidade da dominação política, econômica e cultural de alguns grupos específicos. Enquanto não se verificarem as condições objetivas mínimas para mulheres e negros competirem em pé de igualdade com homens brancos e ricos, as medidas corretivas de acesso à política serão os únicos instrumentos efetivos para alterar a composição do corpo legislativo e para impulsionar mudanças substantivas noutras estruturas externas à esfera política.

Do ponto de vista teórico, objeções podem ser levantadas quanto ao real alcance desses achados para o avanço da agenda feminista e negra no Brasil. Entre outras, encontra-se a questão da "falsa consciência" (YOUNG, 2000), que desvirtuaria a identificação dos "verdadeiros interesses" desses grupos marginalizados. Por exemplo, estaria realmente representando os interesses e direitos de suas eleitoras uma deputada negra que, por motivos religiosos, apresentasse uma proposição legislativa contra a legalização do aborto ou contra a promoção da cultura afro-brasileira, mas que aprovasse leis de promoção da saúde da mulher, de ações afirmativas para negros ou que tornasse mais rígidas as punições contra a violência doméstica cometida contra mulheres negras?

O desenvolvimento recente na literatura que trata gênero e raça como categorias de análise política sugere que estudar a representação substantiva de mulheres e negros é muito mais complicado do que a simples descrição do comportamento parlamentar das/os representantes descritivos. Entender e analisar tal complexidade demandaria a inclusão de um quadro contextual "denso" (thick representation) que incluísse as contingências e situações concretas das mulheres e negros no Brasil (MACKAY, 2008).

Sabe-se, por exemplo, o Brasil ocupa a quinta posição em número de feminicídio num ranking de 83 países. Cerca de 4.657 mulheres foram vítimas de Crimes Violentos Letais intencionais (CVLI) e 49.497 foram estupradas em 2016, o que corresponde a 7 mortes e 135 estupros por dia. Por outro lado, os negros possuem chances $23,5 \%$ maiores de serem assassinados em relação a brasileiros de outras raças, já descontado o efeito 
da idade, escolaridade, sexo, estado civil e bairro de residência. Isso significa que jovens e negros do sexo masculino continuam sendo assassinados todos os anos como se vivessem em situação de guerra (IPEA, 2017).

Diante de tal tragédia, especular se as leis aprovadas (Tabela 4) são ou não fruto da "falsa consciência" ou se têm o condão de realmente promover uma "agenda autenticamente feminista", equivale a um jogo de palavras estéril que sugere uma abordagem elitista descolada do cotidiano da esmagadora maioria de mulheres e negros do país, que simplesmente lutam para permanecer vivos ou não serem estupradas. Excluir ou "filtrar" do quadro analitico desta pesquisa proposições consideradas "antifeministas" por certa literatura, seria enviesar os resultados e subestimar a força do conservadorismo de cunho religioso das camadas menos favorecidas da população negra e feminina do Brasil. 


\section{Bibliografía}

AALBERG, Toril e JENSSEN, Anders Todal. Gender Stereotyping of Political Candidates: An Experimental Study of Political Communication. Nordicom Review vol. 28 n. 1, pp. 17-32, 2007.

ARAÚJO, Clara. As cotas por sexo para a competição legislativa: O caso brasileiro em comparação com experiências internacionais. Dados, vol. 44, n. 1, pp. 155-94, 2001.

BAILEY, Stanley. Legacies of race: Identities, attitudes, and politics in Brazil. Stanford, CA: Stanford University Press, 2009.

BILGE, Sirma. De l'analogie à l'articulation: théoriser la différenciation sociale et l'inégalité complexe. L'Homme et la Société, vol. 2, n.176, pp. 43-64, 2010.

BILLAND, Jan e PAIVA, V. S. Facciolla. Desconstruindo expectativas de gênero a partir de uma posição minoritária: como dialogar com homens autores de violência contra mulheres? Ciência \& Saúde Coletiva, vol. 22, n. 9, pp. 2979-2988, 2017.

CATHO, Instituto. Pesquisa Salarial março de 2017 [Online]. Disponível em: https://www.catho.com.br/empresas/pesquisa-salarial. Acesso em: $06 / 11 / 2018$.

CIG, Comissão para a Cidadania e igualdade de gênero em Portugal: indicadores chave. Presidência do Conselho de Ministros, 2017 [Online]. Disponivel em: https://eeagrants.cig.gov.pt/documentos. Acesso em $09 / 10 / 2018$.

CRENSHA, Kimberle. Demarginalizing the intersection of race and sex; a black feminist critique of discrimination doctrine, feminist theory and antiracist politics. University of Chicago Legal Fórum, pp. 139-167, 1989 [Online]. https://chicagounbound.uchicago.edu/cgi/viewcontent.cgi?article $=1052 \& \mathrm{c}$ ontext=uclf. Acesso em: 22/04/2018.

DAHL, Robert. A Democracia e seus criticos. São Paulo: Martins Fontes. 
FIGUEIREDO, Argelina; LIMONGI, Fernando. Partidos politicos na Câmara dos Deputados: 1989-1994. Dados, vol. 38, n. 3, pp. 497-525, 1998.

Executivo e Legislativo na nova ordem constitucional. Rio de Janeiro (RJ): FGV/FAPESP, 1999.

Constitutional change, legislative performance and institutional consolidation. Brazilian Review of Social Sciences, special issue, no. 1, 2000.

FRANCESHET, Susan.; KROOK, Mona. and JENNIFER, Piscopo. (eds.). The Impact of Gender Quotas. New York, NY: Oxford University Press, 2012.

FRANCESCHET, Susan.; PISCOPO, J. M. Gender Quotas and Women's Substantive Representation: Lessons from Argentina. Politics \& Gender, vol. 4, n. 1, pp. 393-425, 2008.

GILLIGAN, Carol. In a Different Voice. Cambridge (Mass.): Harvard University Press, 1982.

GOMÁRIZ, Enrique.; MEENTZEN, Angela. (Ed.) Democracia de género: una propuesta inclusiva. El Salvador, Ediciones Böll, 2003.

HANCHARD, Michel (ed.) Racial Politics in Contemporary Brazil. Durham: Duke University Press, 1999.

IBGE, Instituto Brasileiro de Geografia e Estatística. Características étnicoraciais da população, 2014 [Online]. Disponivel em: http://www.ibge.gov.br/home/estatistica/populacao/caracteristicas_raciais /default_raciais.shtm. Acesso em: 02/05/2018.

IPEA, Instituto Brasileiro de Pesquisa Econômica Aplicada. Atlas da Violência 2017 [Online]. Rio de Janeiro, 2017. Disponível em:

https://drive.google.com/file/d/OBzuqMfbpwX4wOGQtTmp1SWdXWmM/vi ew. Acesso em 31/10/2017. 
KRAUSE, Susana; DANTAS, Humberto; MIGUEL, Luís Filipe. (Eds.). Coligações partidárias na nova democracia brasileira: perfis e tendências. Rio de Janeiro: Fund. Konrad Adenauer; São Paulo: UNESP, 2010.

KROOK, Mona e ZETTERBERG, Pär. Electoral quotas and political representation: Comparative perspectives. International Political Science Review, vol. 35, n. 1, pp. 3-11, 2014.

IBGE, Instituto Brasileiro de Geografia e Estatística. (2014). Características étnico-raciais da população [Online], 2014. Disponível em: http://www.ibge.gov.br/home/estatistica/populacao/caracteristicas_raciais /default_raciais.shtm. Acesso em: 02/05/2018.

LLANOS, Beatriz e SAMPLE, Kristen. From words to action: Best Practices for Women's Participation in Latin American Political Parties [Online]. Stockholm (SWE): IDEA, 2008. Disponivel em: https: / /www.idea.int/ sites/default/files/publications/from-words-toaction-womens-participation-in-latin-american-political-parties.pdf. Acesso: $21 / 10 / 2019$.

MACKAY, Fiona. "Thick" conceptions of substantive representation: women, gender and political institutions. Journal of Representative Democracy, vol. 44, n. 2, pp. 125-139, 2008.

MAINWARING, Scott; MENEGUELLO, Rachel R.; POWER, Timothy. Partidos conservadores no Brasil contemporâneo. São Paulo: Paz e Terra, 2000.

MOREIRA, Adilson José. O que é discriminação? Belo Horizonte (MG): Letramento, 2017.

NOVAES, Carlos Alberto Marques. Dinâmica institucional de representação. São Paulo (SP): Cebrap, 1994.

PHILLIPS, Anne. The Politics of Presence. Oxford, UK: Oxford University Press, 1995.

PITKIN, Hannah. The concept of Representation. Berkeley and Los Angeles: University of California Press, 1967. 
PLUTZER, Eric e ZIPP, John. Identity politics, partisanship, and voting for women candidates. Public Opinion Quarterly, vol. 60, n. 1, pp. 30-57, 1996.

POPKIN, Samuel. The Reasoning Voter: Communication and Persuasion in Presidential Campaigns. Chicago: University of Chicago Press, 1991.

SACCHET, Tereza. Beyond numbers: The impact of gender quotas in Latin America. International Feminist Journal of Politics, vol. 10, n. 3, pp. 369-386, 2008.

SANSONE, Livio. Blackness Without Ethnicity: Constructing Race in Brazil. New York: Palgrave Macmillan, 2003.

SANTOS, Maria Helena e ESPÍRITO-SANTO, Ana. Para além dos números: Transformações de género associadas à lei da paridade. Journal of Studies on Citizenship and Sustainability, vol. 1 n. 2, pp. 1-34, 2017.

SCOTT, Joan. Gênero: uma categoria útil de análise histórica. Educação e Sociedade, Porto Alegre, vol. 20, n. 2, pp. 71-99, 1995.

SWAIN, Carol. Black faces, black interests: The representation of African Americans in Congress. Cambridge, MS: Harvard University Press, 1993.

TOURAINE, Alain. O que é Democracia? Petrópolis, RJ, Ed. Vozes, $2^{\circ}$ ed. 2007.

TSE, Tribunal Superior Eleitoral, Estatísticas eleitorais 2014. Disponível em: http://www.tse.jus.br/eleicoes/estatisticas/estatisticas-eleitorais-2014eleitorado. Acesso: 01/06/2016.

WÄNGNERRUND, Lena. Women in parliaments: Descriptive and substantive representation. Annual Review of Political Science, vol. 12, n. 2, pp. 5169, 2009.

WINANT, Howard. Racial democracy and racial identity: Comparing the United States and Brazil, in P.H. Collins e J. Solomos (Ed.), Race and ethnic studies (pp. 107-143) London, UK: SAGE, 1999. 
Representação substantiva de gênero e raça no Brasil | Orlando Lyra

YOUNG, Iris Marion. (2000). Inclusion and Democracy. Oxford: Oxford University. 